\title{
Staphylococcus aureus from 152 cases of bovine, ovine and caprine mastitis investigated by Multiple-locus variable number of tandem repeat analysis (MLVA)
}

Dominique Bergonier ${ }^{1,2,3^{*}}$, Daniel Sobral ${ }^{4,5,6}$, Andrea T Feßler $^{7}$, Eric Jacquet ${ }^{8}$, Florence B Gilbert ${ }^{9}$, Stefan Schwarz ${ }^{7}$, Michaël Treilles ${ }^{10}$, Philippe Bouloc ${ }^{4,5}$, Christine Pourcel ${ }^{4,5}$ and Gilles Vergnaud ${ }^{4,5,11^{*}}$

\begin{abstract}
Staphylococcus aureus is one of the main etiological agents of mastitis in ruminants. In the present retrospective study, we evaluated the potential interest of a previously described automated multiple loci Variable Number of Tandem Repeats (VNTR) Assay (MLVA) comprising 16 loci as a first line tool to investigate the population structure of $S$. aureus from mastitis. We determined the genetic diversity of $S$. aureus strains from cases of clinical and subclinical mastitis in dairy cattle $(n=118$, of which 16 were methicillin-resistant), sheep $(n=18)$ and goats $(n=16)$. The 152 strains could be subdivided into 115 MLVA genotypes (including 14 genotypes for the ovine strains and 15 genotypes for the caprine strains). This corresponds to a discriminatory index (D) value of 0.9936. Comparison with published MLVA data obtained using the same protocol applied to strains from diverse human and animal origins revealed a low number (8.5\%) of human-related MLVA genotypes among the present collection. Eighteen percent of the S. aureus mastitis collection belonged to clonal complexes apparently not associated with other pathological conditions. Some of them displayed a relatively low level of diversity in agreement with a restricted ecological niche. These findings provide arguments suggesting that specific $S$. aureus lineages particularly adapted to ruminant mammary glands have emerged and that MLVA is a convenient tool to provide a broad overview of the population, owing to the availability via internet of databases compiling published MLVA genotypes.
\end{abstract}

\section{Introduction}

Although several bacterial pathogens can cause mastitis, Staphylococcus aureus is one of the most prevalent etiologic agents of this disease in dairy cattle [1], and the most important in terms of frequency and clinical severity in goats and sheep [2,3]. As an agent of intra-mammary infections, this pathogen can contaminate the bulk milk tank and thus may constitute a bacteriological hazard for raw milk dairy products consumed. In this context, molecular subtyping tools are of great interest for the comparison of genotypes in order to identify sources and transmission routes for control improvement.

\footnotetext{
* Correspondence: d.bergonier@envt.fr; gilles.vergnaud@u-psud.fr 'INRA, UMR1225, IHAP, 31076 Toulouse, France

${ }^{4}$ Université Paris-Sud, Institut de Génétique et Microbiologie, UMR 8621, 91400 Orsay, France

Full list of author information is available at the end of the article
}

During the past decade, the epidemiology of S. aureus mastitis in dairy cattle has been studied using various molecular typing methods. Techniques that rely on the comparison of electrophoretic patterns, such as Pulsed-Field Gel Electrophoresis (PFGE) [4-6], Random Amplification of Polymorphic DNA (RAPD) analysis [7], ribotyping [5,8] and Multi-Locus Enzyme Electrophoresis (MLEE) [9] proved to be highly discriminatory. Nevertheless the comparison between laboratories of pattern-producing assays is difficult from the data quantification and sharing points of view since they require the implementation of very strict protocols. Sequence-based typing systems such as Multiple Locus Sequence Typing (MLST) or spa typing overcome these problems by producing sharable and easily storable numeric-format results [10-13]. MLST is based on partial sequencing of seven housekeeping genes. spa typing is based on sequencing of a highly polymorphic tandem 
repeat locus showing internal variations of repeat units. When applied to S. aureus, MLST has a low discriminatory power for a relatively high cost, so that some investigators are evaluating the practical feasibility of replacing MLST by whole genome sequence analysis [14,15]. spa locus typing alone is not always a robust indicator of genetic background, as illustrated for instance in an ST398 investigation [16] and is often used in combination with MLST [17]. During the last few years, different Multiple Loci VNTR (Variable Number of Tandem Repeats) Analysis (MLVA) schemes were developed for S. aureus subtyping [18-20] and represent a promising alternative or complement to MLST and spa. In addition to its much higher discriminatory power as compared to previous techniques, MLVA was able to correctly predict clonal complex (CC) assignment and consequently benefit from the strong phylogenetic content provided by MLST analysis [19]. Automated capillary-based MLVA assays for S. aureus genotyping using 8 or 16 VNTR loci have been published $[21,22]$. The second assay, called MLVA16 $6_{\text {Orsay }}$ was demonstrated as being highly suitable for genotyping $S$. aureus isolates from human, animal and food sources [22].

In recent years several MLST-based studies investigating mastitis $[6,13,23]$ have shown the existence of an important host-specificity of $S$. aureus strains. These studies described CC including S. aureus mainly isolated from humans (CC7, CC8, CC22, CC25, CC30, CC45 and CC51) or animals (CC9, CC20, CC97, CC126, CC133 and CC705) [11,24-27]. Regarding mastitis, bovine strains are usually associated with a few CC (including CC97, CC126, CC130, CC133 and CC705) whose specificity for the mammary gland was either low or undefined [22].

The aim of the present study was to use MLVA for the first time to infer a population structure of $S$. aureus strains from mastitis in dairy cows, goats and sheep from different countries and regions. Through the additional information provided by the analysis of VNTR allele distribution, the objective was also to better identify the evolution and emergence of host-adapted or udder-adapted clones.

\section{Materials and methods}

\section{Bacterial strains}

The 152 strains investigated in this retrospective study were obtained from cases of bovine $(n=118)$, ovine $(n=$ $18)$ and caprine $(n=16)$ clinical or subclinical mastitis. An additional table file shows this in more detail (see Additional file 1). Forty-eight among the bovine strains were collected all over Germany between 2006 and 2009. Nineteen were collected in southern Brazil in 1992 and 1993, and 51 in western France in 2008 and 2009. Sixteen German strains collected in 2009 from different locations were previously described as MRSA ST398 [28]. Characteristics of the 19 Brazilian strains were described by Lange et al. [5]. The ovine and caprine strains were collected from clinical or subclinical mastitis between 1978 and 2010 in France in the main dairy production areas: 16 strains from center-west or south-east for goats and 18 strains from the Pyrenees, the Massif Central or Corsica for ewes. The strains were selected as pure cultures obtained after mastitic milk cultivation on agar plates. Only one strain per herd or flock was considered for this study (see Additional file 1).

\section{DNA extraction}

Strains were cultured overnight at $37{ }^{\circ} \mathrm{C}$ in Luria Bertani broth. Genomic DNA was extracted by phenol-chloroform extraction or by using the DNeasy tissue kit (Qiagen, Courtaboeuf, France) with lysostaphin (100 mg/L, Ambi products LLC, USA). Nucleic acid quality and concentration were analysed using an ND-1000 spectrophotometer (NanoDrop, Labtech, Palaiseau, France). Diluted samples of $5 \mathrm{ng} / \mu \mathrm{L}$ in distilled water (Braun, Melsungen, Germany) were used as DNA template for PCR amplification.

\section{Genotyping data production and analysis}

The 16 VNTR loci included in MLVA16 $6_{\text {Orsay }}$ were amplified in two multiplex PCR using the CeeramTools ${ }^{\circ}$ Staphylococcus typing kit (Ceeram, La Chapelle sur Erdre, France) as previously described [22]. The typing data file was imported into BioNumerics version 6.6 (AppliedMaths, Sint-Martens-Latem, Belgium). A cut-off value of $45 \%$ similarity was applied to define clusters according to [19]. Simpson's diversity index was used [29]. The MLVA 16 Orsay data derived from the 152 strains of this study were compared to published data obtained with the same method [22] in order to tentatively assign the new strains to MLST CC $[19,22,30]$. In a previous study, 251 S. aureus strains isolated from human $(n=106)$, swine $(n=32)$, poultry $(n=30)$, companion animals $(n=17)$, horse $(n=5)$, small ruminant $(n=11)$, rodent $(n=2)$, cattle $(n=1)$, food $(n=34)$ and food poisoning events $(n=13)$ were characterized by MLVA $16_{\text {Orsay }}$ complemented by MLST and spa typing. This reference dataset is now used to link new strains. All unclustered strains from the present investigation were characterized by MLST and spa typing.

The primers and condition used for the spa tandem repeat amplification and MLST analysis were as previously described $[10,31,32]$. The amplicons were purified using the QIAquick PCR purification kit (Qiagen, Courtabœuf, France) and sequenced (Eurofins MWG Operon, Ebersberg, Germany or Beckman-Coulter Genomics, Hertfordshire, UK). The spa repeat nomenclature was that of Shopsin et al. [12] and spa types were retrieved from [33]. MLST alleles and sequence types (ST) were identified using the MLST database [34].

Data were analysed by chi-square or Student's $t$-tests. Differences were considered significant when $p<0.05$. 


\section{Results}

\section{MLVA genotypes and epidemiology}

The 152 ruminant strains were resolved into 115 MLVA genotypes with an overall diversity index of 0.9936 . The 118 bovine, 18 ovine and 16 caprine strains belonged to 86, 14 and 15 MLVA genotypes, respectively. One hundred and forty strains fell into twelve clusters, nine of which comprising more than three strains (Figure 1). The clusters were assigned to known MLST-defined CC by comparison with previous MLVA data, spa typing and MLST analysis of selected strains. A dendrogram deduced from the clustering of the $152 \mathrm{~S}$. aureus mastitis-associated strains is presented in Figure 2. CC97 and CC133 accounted for 22\% (34 strains) and 21\% (32 strains) of the studied collection, respectively. CC1, CC9, CC20, CC130, CC151, CC398 and CC479 together represented another $45 \%$ of the strains. The 16 ST398 MRSA strains were distributed into eight MLVA genotypes and three spa types. CC8 and CC30, frequently associated with human $S$. aureus infections, and CC425 a common ovine genotype (Figure 1), were represented by two strains each.

Among the singletons, seven could be assigned to CC5, CC7, CC22, CC25, CC50, CC59 or CC78 by comparison with previously typed isolates (Figure 3 ). Five singletons remained unclustered.
Figure 1 shows the distribution of the strains according to the host. CC130 comprised exclusively small ruminant $S$. aureus strains. Sheep strains (collected from four flocks between 1997 and 2010) and goat strains (collected from six herds in 2004) were segregated by MLVA typing. These ten strains came from three different French husbandry regions without any contact with each other. CC1, CC8, CC9, CC20, CC97, CC151, CC398 and CC479 included only bovine strains. CC133 was the sole cluster showing complete host diversity: 13 bovine strains originating from different collection sites (11\% of the bovine isolates), eleven sheep strains (61\% of the ovine isolates) and eight goat strains (50\% of the caprine strains) belonged to this CC. The remaining small ruminant strains were clustered in CC30, CC425 or were singletons. Only one MLVA genotype comprised strains of two different host species: the cow and goat (MLVA genotype 43, MLST CC133). No MLVA genotype was common to goat and sheep.

Bovine isolates from the three countries fell into 6 up to 10 different CC; small ruminant isolates fell into 3 or 4 CC. The CC distribution was different between Germany, France and Brazil $(p<0.001)$.

Figure 3 shows the comparison of the population structure of $S$. aureus strains from mastitis with the

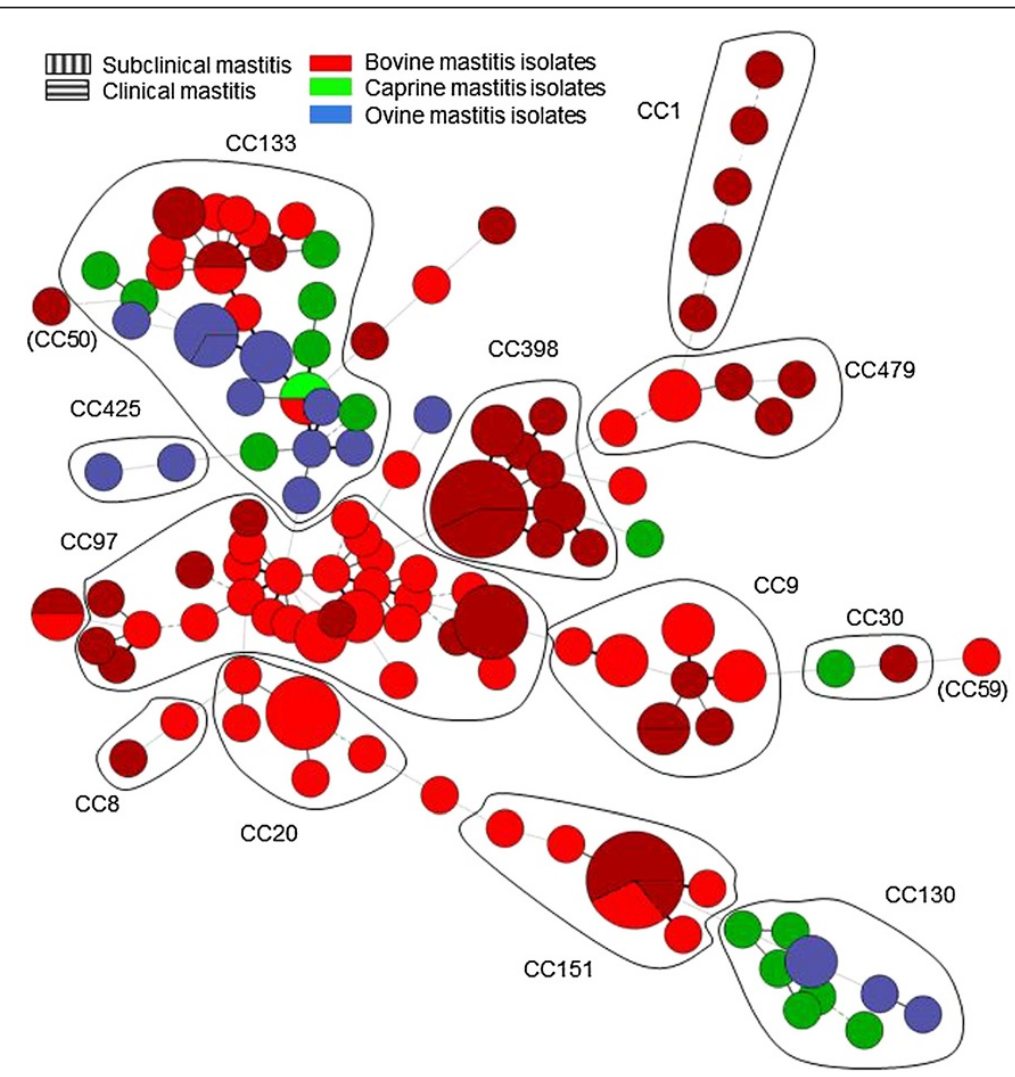

Figure 1 Minimum spanning tree of the 152 S. aureus strains using MLVA16 orsay. Each circle represents an MLVA genotype. The genotypes are coloured according to their host. Major CC are indicated. 
Figure 2 Dendrogram deduced from the clustering of the 152 S. aureus mastitis-associated strains using MLVA16 Orsay The colour code reflects MLVA clusters when using the $45 \%$ cut off. ID: strain identification. spa: spa type. MT: MLVA types. MetR: methicillin-resistance. MRSA: methicillin-resistant Staphylococcus aureus. MSSA: methicillin-susceptible Staphylococcus aureus. C-R: Country-Region. F: France, A: Aveyron, Co: Corse, PA: PyrénéesAtlantiques, AHP: Alpes de Haute-Provence, V: Vienne, CR: Charentes-Maritimes, DS: Deux-Sèvres, IL: Indre-et-Loire, M: Manche, C: Calvados, Ma: Mayenne. B: Brazil, RGS: Rio Grande do Sul. G: Germany, Mu: Mutzenich, Lichtenfels: L, Waldeck: W, Marksuhl: Mark. Reinhardshagen: R, Haag: H, Neustadt: N, Langen: La, Sulza: S, Burstadt: B. Bad Soden-Salmunster: BS, Silberfeld: Sb, Lehrte: Le, Babenhausen: Ba, Huttenberg: H, Wiesenthal: Wi, Raesfeld: Ra, Eurasburg: E, Meinhard: Me, Pfronten: P, Kirchhain: K, Wunstorf: Wu, Ehrenberg: EH, Willingen: Wi, Bodelwitz: Bo, Ebersberg: Eb, Hademar: Ha, Schlitz: Sc, Hofbieber: Ho, Ringgau: Ri, Satteldorf: Sa, Baden-Wurttenberg: BW, Bunde: Bu, Osterberg: O, Farven: F, Melle: Me, Bayern: Ba, Petershagen: PH, Westerstede: We, Lorup: Lo.

more global population of $S$. aureus strains for which MLVA data was available [22]. Some clusters such as CC8, CC22 and CC45 were highly human specific. $\mathrm{CC} 30$ is in an intermediate situation, in agreement with some previous observations [35]. In contrast, CC133 was mainly represented by animal strains, and CC130 by small ruminant mastitis strains. CC97 comprised the largest number of bovine mastitis strains.

\section{VNTR allele distribution analysis}

We calculated the allelic diversity of each VNTR within three groups: human, animal and mammary gland-related strains. The number of alleles per locus was not significantly different between human-related and animal-related clusters, but was significantly reduced in the population of the mammary gland-predominant clusters $(p<0.005)$. The diversity indexes were lower in the latter than in the human-related $(p<0.05)$ or animal-specific (NS) clusters. An additional table file shows this in more detail (see Additional file 2). We also measured the mean number of repetitions per locus and per group. No significant difference was observed between human-predominant and animal-predominant clusters. Differences were noticed when focusing on mammary gland-adapted clusters. This population had a smaller number of repeat units for two VNTR, Sa0122 $(p<0.001)$ and Sa0387 $(p<$ 0.0001 ). An additional file shows this in more detail (see Additional file 3).

\section{Discussion}

\section{CC130, CC151 and CC479 are strongly associated to mastitis}

In the present collection of strains, only 13 (8.6\%) from six different lineages (six $\mathrm{CC} 1$, two $\mathrm{CC} 8$, two $\mathrm{CC} 30$ and single $\mathrm{CC}$, CC22 and $\mathrm{CC} 25$ ) might be of human origin. 


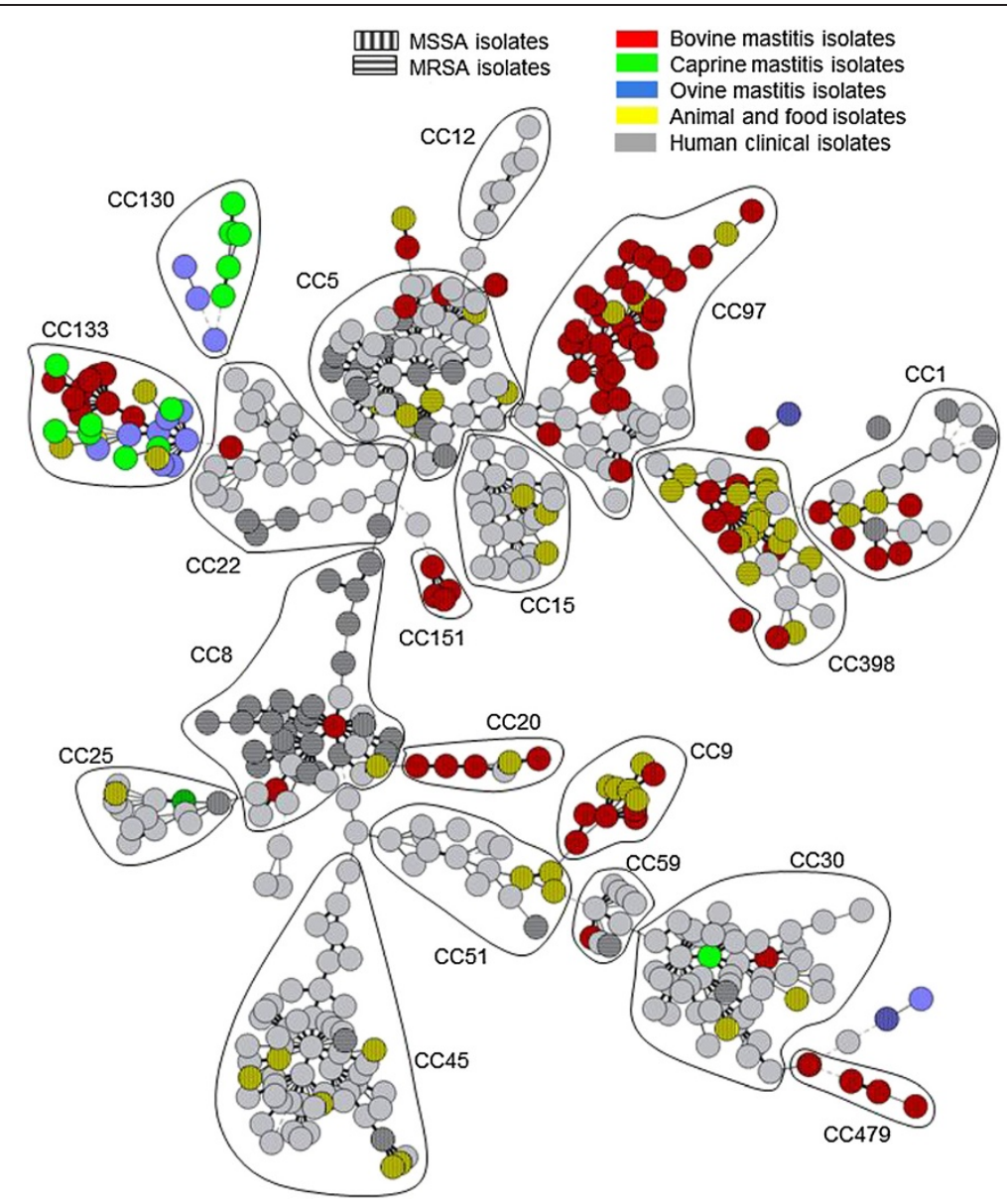

Figure 3 Mastitis strains superimposed on a background of previously published data from human, animal or food isolates [22]. Main CC are indicated. MRSA: methicillin-resistant Staphylococcus aureus. MSSA: methicillin-susceptible Staphylococcus aureus. MRSA and MSSA isolates are highlighted with two different hatch patterns.

Among these lineages, CC30 has also been shown to be established in swine [35]. Devriese observed specific phenotypic characteristics associated with animal S. aureus strains and subsequently emphasized the existence of ecovars adapted to particular host species [36]. Several studies have identified the existence of $S$. aureus CC that are associated with cows, sheep and goats, and rarely isolated from humans, suggesting that ruminants are the preferred hosts $[6,7,9,37]$. Conversely, a number of CC shows limited host specificity. Representatives of some animalpredominant $\mathrm{CC}$ have spread recently with apparently neither strong host nor geographical barriers. In this study, we reported 35 strains belonging to these well-known CC (16 strains from CC398, eleven strains from CC9 and eight strains from CC20). ST398, a cause of human MRSA infections most often associated with livestock exposure, is hypothesized to have emerged from swine but presumably originates from humans. The jump from humans to livestock was probably accompanied by the acquisition of methicillin and tetracycline resistances [38]. CC20 strains represent approximately $1 \%$ of human carriage $[39,40]$ and infections [41] but are also often sampled from cow mastitic milk $[26,42,43]$.

Almost half of the collection studied belonged to two major animal-predominant CC (CC97 and CC133). Twenty-nine and 26 MLVA16 genotypes were observed for a total of 34 CC97 strains and 32 CC133 strains respectively. CC97 is a widespread bovine lineage largely responsible for bovine mastitis cases in Chile, Brazil, Japan and the United States $[13,44]$, and also recently isolated from human [45] and porcine hosts [46]. CC133 is commonly sampled from milk produced by small ruminants $[6,47]$ and by cows (15 among the 33 CC133 strains are from bovines) $[37,48]$ suffering from mastitis.

In the present study, we identified three additional clusters putatively showing strong association with the mammary gland tissue: the "bovine" CC151 (eleven strains) and CC479 (six strains), and the "small ruminants" CC130 (ten strains). All together, they represent 18\% of the present collection. These lineages have almost never been isolated 
from humans and, moreover, were almost exclusively sampled from intramammary infections [25,37,49-51], with one published exception (nasal cavity) [52]. The rare CC479 was not mentioned as mastitis-associated [22]. Interestingly, whole genome analysis demonstrated that CC130 and CC151 are closely related [49] in agreement with MLVA clustering. Several studies revealed that a few CC are responsible for most mastitis cases $[6,7,9]$. Van Leeuwen et al. hypothesized that traits shared by bovine and small ruminant mastitis strains were related to tissue specificity. This would explain that mastitis-associated strains from these farm animal species formed a distinct genetic cluster [53]. These CC have a broad geographical distribution: in the present study, the CC151-MLVA genotype 2-5-3-1-2-2-2-1-9-3-7-0.5-1-0.5-3-1 was shown to be shared by strains sampled in Germany and France.

From the population structure point of view, one must remain careful when interpreting the observation of a small number of CC comprising the majority of livestock and especially mammary isolates. Recently, a single publication identified $9 \mathrm{CC}$ and $4 \mathrm{ST}$ in ovine and caprine mastitis [51], whereas the variability of small ruminant mammary $\mathrm{CC}$ was previously thought to be restricted to two CC (CC130, CC133) according to a review published earlier in the same year [27]. Thus, for each host species, the size of the world target population (livestock) and of the analyzed samples is important to consider, just like its representativeness and the variability of the husbandry systems. For instance the literature on small ruminant $S$. aureus carriage is very limited as compared to humans.

\section{VNTR as genetic markers to infer lineage emergence}

It has been proposed that a low level of VNTR genetic diversity inside a lineage may reflect recent emergence, and that there exists a tendency toward the shortening of tandem repeat array during evolution (such as in Mycobacterium tuberculosis, [54]). Interestingly, we noticed that the mammary gland-predominant lineages (CC130, C151 and CC479) exhibit a smaller repeat unit number per locus and a lower diversity index as compared to other lineages. These observations are most striking in the case of CC151 (Additional file 3). Modifications in industrial livestock husbandry of dairy ruminants could have led to modified access of microbial flora to mammary glands leading to the emergence of some CC such as CC151. Analysis of RF122 strain (ST151) genome sequence provided evidence that this mammary-gland-adapted strain had recently diversified from an ancestor with a supposed human origin through acquisition of mobile genetic elements and gene decay [55,56]. Because tandem repeat mutation rates have been suggested to vary within different lineages in some bacterial species [57], whole genome sequence analysis of well-chosen strains will be necessary to correlate tandem repeat diversity and more neutral genome diversity in S. aureus. Indeed in a preliminary study, we observed that at least some tandem repeats may have an effect on the transcription level of adjacent genes indicating that they are not neutral. Within the same CC, the transcription level of the gene located immediately downstream from Sa0906 was five-fold higher in a strain with four repeat units as compared to a strain with one repeat unit (Vergnaud et al. unpublished; [58]).

\section{Interest of MLVA as a subtyping tool for improving the efficiency of mastitis control}

The characterization of mastitis transmission models (contagious versus environmental herd mastitis) is a critical point to implement relevant control measures. In the case of $S$. aureus, generally classified as a contagious pathogen, the molecular epidemiology profile is in some herds of the environmental type [59]. Taking advantage of the possibility offered by MLVA to efficiently discriminate field isolates, we suggest comparing, in seriously affected herds, various isolates originating from intramammary infections, teat skin, milking machine clusters and the environment. Fournier et al. [60] demonstrated an association between genotypes and mastitis clinical outcome. This original result regarding the accessory genome (presence or absence of toxins) would benefit from the application of the coregenome genotyping achieved by MLVA for identification of particular epidemic or virulent strains. The relatively low cost of MLVA typing and the availability of freely accessible databases on the internet may help enlarge our knowledge on these points [61,62].

\section{Additional files}

\begin{abstract}
Additional file 1: List of Staphylococcus aureus strains used in the study and genotyping data. For each strain, host, isolation year, geographic origin (region and country), mastitis clinical type, collection origin, CC and MLVA type are given. The 152 strains were isolated between 1992 and 2009 in three countries (Germany, France and Brazil) from mastitic-milk of cows, ewes and goats.

Additional file 2: Allelic richness and diversity per locus for each group of strains (human-related, animal-specific, mammary glandadapted). For the three groups of strains, the number of alleles and the diversity index are given for each VNTR.

Additional file 3: Mean number of repeat units per locus and for each group (human-predominant, animal-predominant, mammary gland-predominant). For each VNTR, the number of repeat units (mean and standard deviation) are presented for human-, animal- and mammary gland (mastitis)-predominant strains. CC151, belonging to the latter group, is also presented alone.
\end{abstract}

Competing interests

DS holds stocks from Ceeram. DS and CP have patent licensing arrangements with Ceeram. The other authors declare that they have no competing interests. The funding bodies had no role in the study design, in the collection, analysis and interpretation of data; in the writing of the manuscript or in the decision to submit the manuscript for publication. 


\section{Authors' contributions}

$D S, P B, G V$ and $C P$ conceived and designed the experiments. DS and EJ performed the experiments. DS, DB, EJ, CP and GV analyzed the data. DB, SS, FBG, AF and MT contributed to the preparation and/or the utilization of reagents, materials or analysis tools. DS, DB, GV and CP wrote the article. All authors read and approved the final version.

\section{Acknowledgements}

We thank Fabienne Loisy-Hamon and Benoit Lebeau from the Ceeram company for their support to this project. This includes the cost of the MLVA typing of all S. aureus isolates. The contributions of SS and ATF are financially supported by the German Federal Ministry of Education and Research (BMBF) through the German Aerospace Center (DLR), grant number 01KI1301D (MedVet-Staph II). This study also benefited from the support of the association "Vaincre La Mucoviscidose" (Grant N RC0630) This work has benefited from the facilities and expertise of IMAGIF (Centre de Recherche de Gif). The development of tools for the surveillance of bacterial pathogens is supported by the French Direction Générale de I'Armement (DGA). We thank Roswitha Becker, Vivian Hensel and MarieClaude Hygoneng for excellent technical assistance. We thank Chantal Bohn for helpful discussions on S. aureus RNA analysis and Xavier Berthelot for helpful discussions on dairy ruminants intramammary infections.

\section{Author details}

'INRA, UMR1225, IHAP, 31076 Toulouse, France. '2Université de Toulouse, INP, ENVT, UMR1225, IHAP, 31076 Toulouse, France. ${ }^{3}$ UMT INRA-ENVT-Institut de I'Élevage "Small Ruminants Health Management", 31076 Toulouse, France. ${ }^{4}$ Université Paris-Sud, Institut de Génétique et Microbiologie, UMR 8621, 91400 Orsay, France. ${ }^{5} \mathrm{CNRS}$, Orsay, France. ${ }^{6}$ Ceeram (Centre Européen d'Expertise et de Recherche sur les Agents Microbiens), 44240 La Chapelle sur Erdre, France. ${ }^{7}$ Institute of Farm Animal Genetics,

Friedrich-Loeffler-Institute, 31535 Neustadt-Mariensee, Germany. ${ }^{8}$ ICSN, CNRS, UPR2301, IMAGIF qPCR-Platform, 91198 Gif-sur-Yvette, France. 'INRA UMR1282, ISP, 37380 Nouzilly, France. ${ }^{10}$ Laboratoire départemental d'analyses de la Manche (LDA50), 50000 Saint-Lô, France. ${ }^{11}$ ENSTA ParisTech, 91762 Palaiseau, France.

Received: 24 December 2013 Accepted: 5 September 2014

Published online: 02 October 2014

\section{References}

1. Wilson DJ, Gonzalez RN, Das HH: Bovine mastitis pathogens in New York and Pennsylvania: prevalence and effects on somatic cell count and milk production. J Dairy Sci 1997, 80:2592-2598.

2. Bergonier D, de Cremoux R, Rupp R, Lagriffoul G, Berthelot X: Mastitis of dairy small ruminants. Vet Res 2003, 34:689-716.

3. de Almeida LM, de Almeida MZ, de Mendonça CL, Mamizuka EM: Novel sequence types (STs) of Staphylococcus aureus isolates causing clinical and subclinical mastitis in flocks of sheep in the northeast of Brazil. J Dairy Res 2011, 78:373-378.

4. Annemuller C, Lammler C, Zschock M: Genotyping of Staphylococcus aureus isolated from bovine mastitis. Vet Microbiol 1999, 69:217-224

5. Lange C, Cardoso M, Senczek D, Schwarz S: Molecular subtyping of Staphylococcus aureus isolates from cases of bovine mastitis in Brazil. Vet Microbiol 1999, 67:127-141.

6. Jørgensen HJ, Mørk T, Caugant DA, Kearns A, Rorvik LM: Genetic variation among Staphylococcus aureus strains from Norwegian bulk milk. Appl Environ Microbiol 2005, 71:8352-8361.

7. Fitzgerald JR, Meaney WJ, Hartigan PJ, Smyth CJ, Kapur V: Fine-structure molecular epidemiological analysis of Staphylococcus aureus recovered from cows. Epidemiol Infect 1997, 119:261-269.

8. Larsen HD, Sloth $\mathrm{KH}$, Elsberg C, Enevoldsen C, Pedersen LH, Eriksen NH, Aarestrup FM, Jensen NE: The dynamics of Staphylococcus aureus intramammary infection in nine Danish dairy herds. Vet Microbiol 2000, 71:89-101.

9. Kapur V, Sischo WM, Greer RS, Whittam TS, Musser JM: Molecular population genetic analysis of Staphylococcus aureus recovered from cows. J Clin Microbiol 1995, 33:376-380.

10. Enright MC, Day NP, Davies CE, Peacock SJ, Spratt BG: Multilocus sequence typing for characterization of methicillin-resistant and methicillin-susceptible clones of Staphylococcus aureus. J Clin Microbiol 2000, 38:1008-1015.
11. Holmes MA, Zadoks RN: Methicillin resistant S. aureus in human and bovine mastitis. J Mammary Gland Biol Neoplasia 2011, 16:373-382

12. Shopsin B, Gomez M, Montgomery SO, Smith DH, Waddington M, Dodge DE, Bost DA, Riehman M, Naidich S, Kreiswirth BN: Evaluation of protein A gene polymorphic region DNA sequencing for typing of Staphylococcus aureus strains. J Clin Microbiol 1999, 37:3556-3563.

13. Smith EM, Green LE, Medley GF, Bird HE, Fox LK, Schukken YH, Kruze JV, Bradley AJ, Zadoks RN, Dowson CG: Multilocus sequence typing of intercontinental bovine Staphylococcus aureus isolates. $J$ Clin Microbiol 2005, 43:4737-4743.

14. Jolley KA, Hill DM, Bratcher HB, Harrison OB, Feavers IM, Parkhill J, Maiden MC Resolution of a meningococcal disease outbreak from whole-genome sequence data with rapid Web-based analysis methods. J Clin Microbiol 2012, 50:3046-3053.

15. Mellmann A, Harmsen D, Cummings CA, Zentz EB, Leopold SR, Rico A, Prior K Szczepanowski R, Ji Y, Zhang W, McLaughlin SF, Henkhaus JK, Leopold B, Bielaszewska M, Prager R, Brzoska PM, Moore RL, Guenther S, Rothberg JM, Karch $\mathrm{H}$ : Prospective genomic characterization of the German enterohemorrhagic Escherichia coli O104:H4 outbreak by rapid next generation sequencing technology. PLoS One 2011, 6:e22751.

16. van Wamel WJ, Hansenova Manaskova S, Fluit AC, Verbrugh $\mathrm{H}$, de Neeling AJ, van Duijkeren E, van Belkum A: Short term micro-evolution and PCRdetection of methicillin-resistant and -susceptible Staphylococcus aureus sequence type 398. Eur J Clin Microbiol Infect Dis 2010, 29:119-122.

17. Hasman H, Moodley A, Guardabassi L, Stegger M, Skov RL, Aarestrup FM: spa type distribution in Staphylococcus aureus originating from pigs, cattle and poultry. Vet Microbiol 2010, 141:326-331.

18. Hardy KJ, Oppenheim BA, Gossain S, Gao F, Hawkey PM: Use of variations in staphylococcal interspersed repeat units for molecular typing of methicillin-resistant Staphylococcus aureus strains. J Clin Microbiol 2006, 44:271-273

19. Pourcel C, Hormigos K, Onteniente L, Sakwinska O, Deurenberg RH, Vergnaud G Improved multiple-locus variable-number tandem-repeat assay for Staphylococcus aureus genotyping, providing a highly informative technique together with strong phylogenetic value. J Clin Microbiol 2009, 47:3121-3128.

20. Melles DC, Schouls L, Francois P, Herzig S, Verbrugh HA, van Belkum A, Schrenzel J: High-throughput typing of Staphylococcus aureus by amplified fragment length polymorphism (AFLP) or multi-locus variable number of tandem repeat analysis (MLVA) reveals consistent strain relatedness. Eur J Clin Microbiol Infect Dis 2009, 28:39-45.

21. Schouls LM, Spalburg EC, van Luit M, Huijsdens XW, Pluister GN, van Santen-Verheuvel MG, van der Heide HG, Grundmann H, Heck ME, de Neeling AJ: Multiple-locus variable number tandem repeat analysis of Staphylococcus aureus: comparison with pulsed-field gel electrophoresis and spa-typing. PLoS One 2009, 4:e5082.

22. Sobral D, Schwarz S, Bergonier D, Brisabois A, Fessler AT, Gilbert FB, Kadlec K, Lebeau B, Loisy-Hamon F, Treilles M, Pourcel C, Vergnaud G: High throughput multiple locus variable number of tandem repeat analysis (MLVA) of Staphylococcus aureus from human, animal and food sources. PLOS One 2012, 7:e33967.

23. Kwon NH, Park KT, Moon JS, Jung WK, Kim SH, Kim JM, Hong SK, Koo HC, Joo YS, Park YH: Staphylococcal cassette chromosome $\mathrm{mec}(\mathrm{SCCmec})$ characterization and molecular analysis for methicillin-resistant Staphylococcus aureus and novel SCCmec subtype IVg isolated from bovine milk in Korea. J Antimicrob Chemother 2005, 56:624-632.

24. Donker GA, Deurenberg RH, Driessen C, Sebastian S, Nys S, Stobberingh EE: The population structure of Staphylococcus aureus among general practice patients from The Netherlands. Clin Microbiol Infect 2009, 15:137-143.

25. Sung JM, Lloyd DH, Lindsay JA: Staphylococcus aureus host specificity: comparative genomics of human versus animal isolates by multi-strain microarray. Microbiology 2008, 154:1949-1959.

26. Hata E, Katsuda K, Kobayashi H, Uchida I, Tanaka K, Eguchi M: Genetic variation among Staphylococcus aureus strains from bovine milk and their relevance to methicillin-resistant isolates from humans. J Clin Microbiol 2010, 48:2130-2139.

27. Fitzgerald JR: Livestock-associated Staphylococcus aureus: origin evolution and public health threat. Trends Microbiol 2012, 20:192-198.

28. Feßler A, Scott C, Kadlec K, Ehricht R, Monecke S, Schwarz S: Characterization of methicillin-resistant Staphylococcus aureus ST398 from cases of bovine mastitis. J Antimicrob Chemother 2010, 65:619-625. 
29. Hunter PR, Gaston MA: Numerical index of the discriminatory ability of typing systems: an application of Simpson's index of diversity. J Clin Microbiol 1988, 26:2465-2466.

30. Riehm JM, Vergnaud G, Kiefer D, Damdindorj T, Dashdavaa O, Khurelsukh T, Zoller L, Wolfel R, Le Flèche P, Scholz HC: Yersinia pestis lineages in Mongolia. PLoS One 2012, 7:e30624

31. Harmsen D, Claus H, Witte W, Rothganger J, Claus H, Turnwald D, Vogel U: Typing of methicillin-resistant Staphylococcus aureus in a university hospital setting by using novel software for spa repeat determination and database management. J Clin Microbiol 2003, 41:5442-5448.

32. Staphylococcus aureus MLST Multi Locus Sequence Typing. [http://saureus. mlst.net/]

33. The Ridom SpaServer. [http://spaserver.ridom.de]

34. The MLST database. [http://www.mlst.net]

35. Armand-Lefevre L, Ruimy R, Andremont A: Clonal comparison of Staphylococcus aureus isolates from healthy pig farmers, human controls, and pigs. Emerg Infect Dis 2005, 11:711-714

36. Devriese LA: A simplified system for biotyping Staphylococcus aureus strains isolated from animal species. J App/ Bacteriol 1984, 56:215-220.

37. Smyth DS, Feil EJ, Meaney WJ, Hartigan PJ, Tollersrud T, Fitzgerald JR, Enright MC, Smyth CJ: Molecular genetic typing reveals further insights into the diversity of animal-associated Staphylococcus aureus. J Med Microbiol 2009, 58:1343-1353.

38. Price LB, Stegger M, Hasman H, Aziz M, Larsen J, Andersen PS, Pearson T, Waters AE, Foster JT, Schupp J, Gillece J, Driebe E, Liu CM, Springer B, Zdovc I, Battisti A, Franco A, Zmudzki J, Schwarz S, Butaye P, Jouy E, Pomba C, Porrero MC, Ruimy R, Smith TC, Robinson DA, Weese JS, Arriola CS, Yu F, Laurent F, Keim P, Skov R, Aarestrup FM: Staphylococcus aureus CC398: host adaptation and emergence of methicillin resistance in livestock. MBio 2012, 3:pii:e00605-11.

39. Ko KS, Lee JY, Baek JY, Peck KR, Rhee JY, Kwon KT, Heo ST, Ahn KM, Song $\mathrm{JH}$ : Characterization of Staphylococcus aureus nasal carriage from children attending an outpatient clinic in Seoul, Korea. Microb Drug Resist 2008, 14:37-44

40. Ruimy R, Armand-Lefevre L, Barbier F, Ruppe E, Cocojaru R, Mesli Y, Maiga A, Benkalfat M, Benchouk S, Hassaine H, Dufourcq JB, Nareth C, Sarthou JL, Andremont A, Feil EJ: Comparisons between geographically diverse samples of carried Staphylococcus aureus. J Bacteriol 2009, 191:5577-5583.

41. Grundmann H, Aanensen DM, van den Wijngaard CC, Spratt BG, Harmsen D, Friedrich AW: Geographic distribution of Staphylococcus aureus causing invasive infections in Europe: a molecular-epidemiological analysis. PLoS Med 2010, 7:e1000215

42. Bystron J, Podkowik M, Korzekwa K, Lis E, Molenda J, Bania J: Characterization of borderline oxacillin-resistant Staphylococcus aureus isolated from food of animal origin. J Food Prot 2010, 73:1325-1327.

43. Sakwinska $O$, Giddey M, Moreillon M, Morisset D, Waldvogel A, Moreillon P. Staphylococcus aureus host range and human-bovine host shift. Appl Environ Microbiol 2011, 77:5908-5915

44. Rabello RF, Moreira BM, Lopes RM, Teixeira LM, Riley LW, Castro AC: Multilocus sequence typing of Staphylococcus aureus isolates recovered from cows with mastitis in Brazilian dairy herds. J Med Microbio/ 2007, 56:1505-1511.

45. Lozano C, Gomez-Sanz E, Benito D, Aspiroz C, Zarazaga M, Torres C: Staphylococcus aureus nasal carriage, virulence traits, antibiotic resistance mechanisms, and genetic lineages in healthy humans in Spain, with detection of CC398 and CC97 strains. Int J Med Microbiol 2011, 301:500-505.

46. Battisti A, Franco A, Merialdi G, Hasman H, lurescia M, Lorenzetti R, Feltrin F, Zini M, Aarestrup FM: Heterogeneity among methicillin-resistant Staphylococcus aureus from Italian pig finishing holdings. Vet Microbiol 2010, 142:361-366

47. Aires-de-Sousa M, Parente CE, Vieira-da-Motta O, Bonna IC, Silva DA, de Lencastre H: Characterization of Staphylococcus aureus isolates from buffalo, bovine, ovine, and caprine milk samples collected in Rio de Janeiro State, Brazil. Appl Environ Microbio/ 2007, 73:3845-3849.

48. Ben Zakour NL, Sturdevant DE, Even S, Guinane CM, Barbey C, Alves PD, Cochet MF, Gautier M, Otto M, Fitzgerald JR, Le Loir Y: Genome-wide analysis of ruminant Staphylococcus aureus reveals diversification of the core genome. J Bacteriol 2008, 190:6302-6317.

49. Guinane CM, Ben Zakour NL, Tormo-Mas MA, Weinert LA, Lowder BV, Cartwright RA, Smyth DS, Smyth CJ, Lindsay JA, Gould KA, Witney A, Hinds J, Bollback JP, Rambaut A, Penades JR, Fitzgerald JR: Evolutionary genomics of Staphylococcus aureus reveals insights into the origin and molecular basis of ruminant host adaptation. Genome Biol Evol 2010, 2:454-466.

50. Ikawaty R, Willems RJ, Box AT, Verhoef J, Fluit AC: Novel multiple-locus variable-number tandem-repeat analysis method for rapid molecular typing of human Staphylococcus aureus. J Clin Microbiol 2008, 46:3147-3151

51. Porrero MC, Hasman H, Vela Al, Fernandez-Garayzabal JF, Dominguez L, Aarestrup FM: Clonal diversity of Staphylococcus aureus originating from the small ruminants goats and sheep. Vet Microbiol 2012, 156:157-161.

52. Eriksson J, Espinosa-Gongora C, Stamphoj I, Larsen AR, Guardabassi L: Carriage frequency, diversity and methicillin resistance of Staphylococcus aureus in Danish small ruminants. Vet Microbiol 2013, 163:110-115.

53. van Leeuwen W, Melles DC, Alaidan A, Al-Ahdal M, Boelens HA, Snijders SV, Wertheim H, van Duijkeren E, Peeters JK, van der Speck PJ, Gorkink R, Simons G, Verbrugh HA, van Belkum A: Host- and tissue-specific pathogenic traits of Staphylococcus aureus isolates. J Bacteriol 2005, 187:4584-4591.

54. Arnold C, Thorne N, Underwood A, Baster K, Gharbia S: Evolution of short sequence repeats in Mycobacterium tuberculosis. FEMS Microbiol Lett 2006, 256:340-346.

55. Herron LL, Chakravarty R, Dwan C, Fitzgerald JR, Musser JM, Retzel E, Kapur V: Genome sequence survey identifies unique sequences and key virulence genes with unusual rates of amino Acid substitution in bovine Staphylococcus aureus. Infect Immun 2002, 70:3978-3981.

56. Herron-Olson L, Fitzgerald JR, Musser JM, Kapur V: Molecular correlates of host specialization in Staphylococcus aureus. PLoS One 2007, 2:e1120.

57. Comas I, Homolka S, Niemann S, Gagneux S: Genotyping of genetically monomorphic bacteria: DNA sequencing in Mycobacterium tuberculosis highlights the limitations of current methodologies. PLoS One 2009, 4:e7815.

58. Sobral D: De l'usage du polymorphisme de répétitions en tandem pour l'étude des populations bactériennes : mise au point et validation d'un système de génotypage automatisé utilisant la technique de MLVA Orsay. Paris Sud University (Molecular Biology); 2012 [http://www.theses.fr/ 2012PA112074].

59. Zadoks RN, Middleton JR, McDougall S, Katholm J, Schukken YH: Molecula epidemiology of mastitis pathogens of dairy cattle and comparative relevance to humans. J Mammary Gland Biol Neoplasia 2011, 16:357-372.

60. Fournier C, Kuhnert P, Frey J, Miserez R, Kirchhofer M, Kaufmann T, Steiner A, Graber HU: Bovine Staphylococcus aureus: association of virulence genes, genotypes and clinical outcome. Res Vet Sci 2008, 85:439-448.

61. MLVAbank. [http://mlva.u-psud.fr]

62. Grissa I, Bouchon P, Pourcel C, Vergnaud G: On-line resources for bacterial micro-evolution studies using MLVA or CRISPR typing. Biochimie 2008, 90:660-668.

\section{doi:10.1186/s13567-014-0097-4}

Cite this article as: Bergonier et al:: Staphylococcus aureus from 152 cases of bovine, ovine and caprine mastitis investigated by Multiple-locus variable number of tandem repeat analysis (MLVA). Veterinary Research 2014 45:97.

\section{Submit your next manuscript to BioMed Central and take full advantage of:}

- Convenient online submission

- Thorough peer review

- No space constraints or color figure charges

- Immediate publication on acceptance

- Inclusion in PubMed, CAS, Scopus and Google Scholar

- Research which is freely available for redistribution 